Tozer, D. C., K. L. Drake, and C. Myles Falconer. 2016. Modeling detection probability to improve marsh bird surveys in southern Canada and the Great Lakes states. Avian Conservation and Ecology 11(2):3. http://dx.doi.org/10.5751/ACE-00875-110203

Copyright (C) 2016 by the author(s). Published here under license by the Resilience Alliance.

Research Paper

\title{
Modeling detection probability to improve marsh bird surveys in southern Canada and the Great Lakes states
}

\author{
Douglas C. Tozer ${ }^{1}$, Kiel L. Drake ${ }^{1}$ and C. Myles Falconer ${ }^{1}$ \\ ${ }^{1}$ Bird Studies Canada
}

\begin{abstract}
Marsh birds are notoriously elusive, with variation in detection probability across species, regions, seasons, and different times of day and weather. Therefore, it is important to develop regional field survey protocols that maximize detections, but that also produce data for estimating and analytically adjusting for remaining differences in detections. We aimed to improve regional field survey protocols by estimating detection probability of eight elusive marsh bird species throughout two regions that have ongoing marsh bird monitoring programs: the southern Canadian Prairies (Prairie region) and the southern portion of the Great Lakes basin and parts of southern Québec (Great Lakes-St. Lawrence region). We accomplished our goal using generalized binomial $N$-mixture models and data from 22,300 marsh bird surveys conducted between 2008 and 2014 by Bird Studies Canada's Prairie, Great Lakes, and Québec Marsh Monitoring Programs. Across all species, on average, detection probability was highest in the Great Lakes-St. Lawrence region from the beginning of May until mid-June, and then fell throughout the remainder of the season until the end of June; was lowest in the Prairie region in mid-May and then increased throughout the remainder of the season until the end of June; was highest during darkness compared with light; and did not vary significantly according to temperature (range: $0-30{ }^{\circ} \mathrm{C}$ ), cloud cover $(0 \%-100 \%)$, or wind ( $0-20 \mathrm{kph})$, or during morning versus evening. We used our results to formulate improved marsh bird survey protocols for each region. Our analysis and recommendations are useful and contribute to conservation of wetland birds at various scales from local single-species studies to the continental North American Marsh Bird Monitoring Program.
\end{abstract}

\section{Modélisation de la probabilité de détection visant l'amélioration des suivis d'oiseaux de marais dans le sud du Canada et les États des Grands Lacs}

RÉSUMÉ. Les oiseaux de marais sont célèbres pour leur moeurs discrètes, entraînant du coup des probabilités de détection variables selon les espèces, les régions, les saisons, le moment de la journée et les conditions météorologiques. Il est donc important d'élaborer des protocoles régionaux de relevé sur le terrain qui maximisent les détections, mais produisent aussi des données permettant d'estimer et d'ajuster analytiquement les différences de détectabilité restantes. Notre objectif était d'améliorer les protocoles régionaux de relevé sur le terrain en estimant la probabilité de détection de huit espèces de marais discrètes dans deux régions hôtes de programmes réguliers de suivis d'oiseaux de marais : le sud des Prairies canadiennes (région des Prairies), et la partie sud du bassin des Grands Lacs et des zones du Québec méridional (région des Grands-Lacs-Saint-Laurent). Pour ce faire, nous avons utilisé des modèles N-mélange binomiaux généralisés et les données de 22300 relevés d'oiseaux de marais réalisés entre 2008 et 2014 dans le cadre des Programmes de surveillance des marais des Prairies, des Grands Lacs et du Québec, chapeautés par Études d'Oiseaux Canada. Parmi toutes les espèces, en moyenne, la probabilité de détection était le plus élevée dans la région des Grands-Lacs-Saint-Laurent du début de mai jusqu'à la mi-juin, puis elle dégringolait jusqu'à la fin de juin; elle était au plus bas dans la région des Prairies à la mi-mai, puis augmentait graduellement jusqu'à la fin de juin. La probabilité de détection était plus élevée à la noirceur qu'à la clarté et n'a pas varié significativement en fonction de la température (étendue : 0 à $\left.30^{\circ} \mathrm{C}\right)$, de la couverture nuageuse $(0 \%$ à $100 \%)$ ou du vent $(0$ à $20 \mathrm{~km} / \mathrm{h})$, ni du moment de la journée (matin ou soir). À partir de nos résultats, nous avons produit des protocoles améliorés de relevé d'oiseaux de marais pour chaque région. Nos analyses et recommandations sont utiles et contribuent à la conservation des oiseaux de milieux humides à des échelles variées allant d'études locales sur une seule espèce au Programme nord-américain de suivi des oiseaux de marais d'envergure continentale.

Key Words: detection probability; marsh bird; $N$-mixture model; waterbird

\section{INTRODUCTION}

In the past decade considerable advances have been made in developing standardized instructions for collecting high-quality monitoring data on elusive marsh birds, known as the Standardized North American Marsh Bird Monitoring Protocol (Conway 2011). Much of the guidance in the protocol is intended to maximize detections through the use of call broadcasts for targeted species, and by conducting surveys at times of day and season when birds are thought to vocalize most frequently. Optimizing surveys to maximize detections in this way is important because it increases the statistical power to estimate parameters of interest and population trends, which are typical goals of marsh bird monitoring programs (Steidl et al. 2013). Thus, ensuring that marsh bird surveys maximize detections across most or all targeted species provides information that can lead to more effective conservation. 
Advances in methods for analyzing bird survey data have also occurred. In particular, we now have a much better understanding of the detection process during surveys (e.g., McCallum 2005), as well as access to freely available software capable of hierarchical modeling of the various components of the process (e.g., Fiske et al. 2015). Detection of marsh birds starts with the probability that sampling units at least partially overlap the home ranges or territories of targeted species. Then there is the probability that the individuals are within sampling units during surveys, the probability that such individuals give cues (most often vocalizations) allowing for their detection during surveys, and finally the probability that observers detect the cues given by such individuals during surveys. The latter three components are often referred to as probability of presence, availability (given presence), and detectability (given presence and availability), respectively, and when combined together in various combinations are typically referred to as detection probability (Nichols et al. 2009).

Most detections of breeding marsh birds are made aurally (Conway and Gibbs 2011). By contrast, visual detections of many species are relatively rare because of the birds' elusive behavior and tendency to inhabit wetlands with dense stands of emergent vegetation. As such, efforts to improve survey protocols by increasing detections tend to focus on identifying times of day and season when the frequency of vocalizations is highest, or in other words, when availability is highest. For instance, Conway (2011) recommends that surveys occur during times of day when marsh birds are most likely to vocalize, and also during times of season when vocalization activity is greatest. Daily and seasonal peaks in vocalizations vary among locations, so the optimal daily and seasonal timing for conducting surveys while maximizing detections is apt to vary regionally (Rehm and Baldassarre 2007, Nadeau et al. 2008). Vocalizations of marsh birds and associated detections are also further influenced by factors such as wind, air temperature, and cloud cover (Conway and Gibbs 2011). Thus, to best monitor this group of elusive species, region-specific information is required on how detections vary in relation to time of day, season, and other factors across different marsh bird species. Such information can be used to make design-based adjustments in field survey protocols to maximize detections, while continuing to collect data to make model-based estimates and associated analytical adjustments for remaining differences in detections.

Southern Canada and the Great Lakes states contain a sizable portion of the continental breeding distributions of many marsh and wetland-associated bird species (Tacha and Braun 1994). As such, there are multiple ongoing long-term marsh bird monitoring programs active throughout an extensive area, including Bird Studies Canada's Prairie, Great Lakes, and Québec Marsh Monitoring Programs (Tozer 2013, 2016, Bird Studies Canada 2016); the Great Lakes Coastal Wetland Monitoring Program (Cooper et al. 2014); and state-level monitoring programs (e.g., Wisconsin Bird Conservation Initiative 2015). Some of these programs have independently developed sampling protocols, whereas others largely follow the standardized North American protocol (Conway 2011), so that the sampling protocols vary. Such variation is perhaps not surprising, because Conway (2011) warned that the standardized North American protocol may need to be refined locally in certain instances such as these. The variation among the different protocols makes it unclear which sampling protocols are best for use across, or within, certain parts of southern Canada and the Great Lakes states. However, we can use recent advances in our understanding and ability to model detections to empirically derive more robust data-driven sampling protocols to overcome the challenges.

To provide clarity, we used data from $\sim 22,300$ marsh bird surveys conducted between 2008 and 2014 to estimate species-specific detection probabilities, and to test the effect of various environmental factors on detection probability. We developed empirically based models for several marsh bird species describing seasonal, daily, and weather-related variation in (1) the probability that individuals are present and available during surveys (hereafter, $\phi$ or availability) and (2) the probability that available individuals are detected by observers during surveys (hereafter, $p$ or detectability). Our goal was to understand the relationship between availability or detectability and explanatory variables to make field protocol recommendations for sampling that would maximize detections of marsh birds in southern Canada and the Great Lakes states. Our ultimate outcome was to produce more effective sampling protocols than have been available to date for researchers and managers charged with targeted monitoring of individual species or entire suites of marsh bird species. As such, our analysis and recommendations are useful at various scales from local single-species studies right up to the continental North American Marsh Bird Monitoring Program.

\section{METHODS}

\section{Study design}

We used data collected by Bird Studies Canada's Prairie, Great Lakes, and Québec Marsh Monitoring Programs (Tozer 2013, Bird Studies Canada 2016). The three programs began at different times, but each has been active since 2008, so we used data from 2008 to 2014 in this study. We focused on two separate regions where there was sufficient spatial coverage for generating recommendations to improve marsh bird surveys. Data for the Prairie region were collected across southern Alberta, Saskatchewan, and Manitoba via the Prairie Marsh Monitoring Program. Data for the Great Lakes-St. Lawrence region were collected across the southern portion of the Great Lakes basin and parts of southern Québec via the Great Lakes Marsh Monitoring Program and the Québec Marsh Monitoring Program. The extent of the two regions spans an area encompassing $12^{\circ}$ of latitude and $45^{\circ}$ of longitude (Fig. 1). Each survey location was assigned to one or the other of the above regions (hereafter a categorical covariate with two levels, referred to as region).

Surveys were conducted within 1-8 circular (Prairie region) or 1-8 semicircular (Great Lakes-St. Lawrence region) plots with a 100$\mathrm{m}$ radius (hereafter, stations) along survey routes within one marsh or across multiple marshes. Most stations ( $90 \%)$ were located on shore and were placed $>250-400 \mathrm{~m}$ apart depending on the program to avoid double-counting individuals in wetlands that were at least partially covered by nonwoody, robust emergent plants (e.g., cattail [Typha sp.]). Survey stations in the Prairie region were selected using a random sample stratified across ecoregions, whereas survey stations in the Great Lakes-St. Lawrence region were selected using various methods including random and haphazard sampling. 
Fig. 1. Survey locations used to form empirically based sampling protocols to maximize detection probability of secretive marsh birds within two regions of southern Canada and the Great Lakes states, 2008 to 2014.

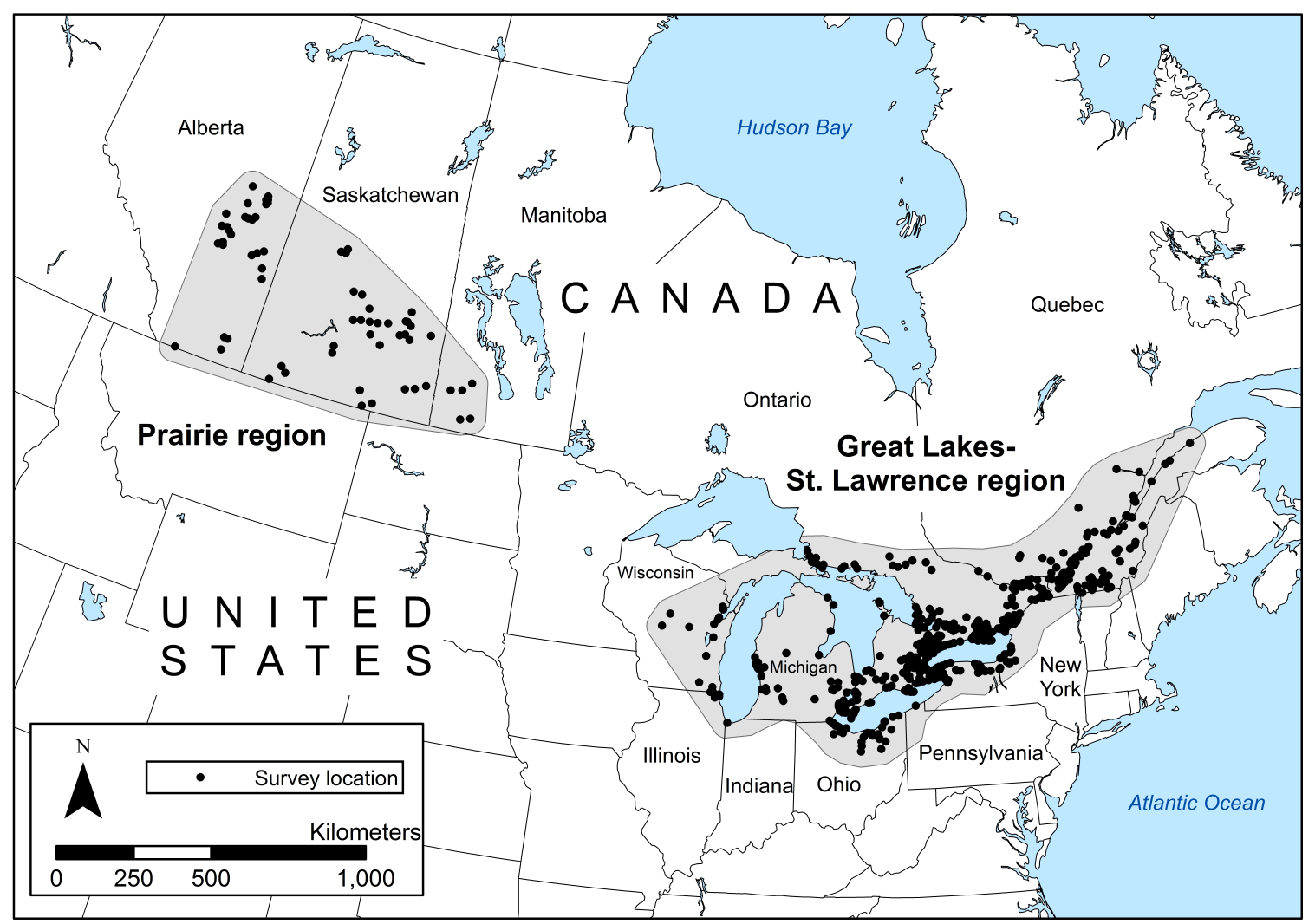

\section{Bird surveys}

Each station was surveyed for 15 min on 2-3 occasions at least 4-10 days apart between visits during May-July in each year that the survey route was active. Surveys occurred in either the morning or the evening and in weather conditions favorable for bird surveys (i.e., wind $<20 \mathrm{kph}$ and no precipitation). Each 15min survey began with 5 min of passive (silent) observation, then 5 min of sampling with species calls being broadcast, followed by a final 5-min passive sampling period. Participants recorded the number of individuals of each species detected during each of the three consecutive 5-min intervals during each 15-min survey. We designated the three consecutive 5-min intervals as a categorical covariate with three levels referred to as survey interval. During each survey, participants recorded a Beaufort wind scale value (hereafter, wind), air temperature in degrees centigrade (hereafter, temperature), and percent cloud cover (hereafter, cloud). For each survey, we also assigned the day of the year (e.g., 20 May = 140; hereafter, date), morning or evening (hereafter a categorical covariate with two levels, referred to as time of day), and time to or since sunrise or sunset, such that negative values were during darkness and positive values were during light (hereafter, daylight).

Participants broadcasted calls during surveys to entice individuals of elusive species to reveal their presence, usually by responding vocally. The composition and sequence of species calls in the broadcast differed depending on the region, but always consisted of $30 \mathrm{sec}$ of vocalizations followed by $30 \mathrm{sec}$ of silence for each species. Call broadcasts in the Prairie region included the following, depending on province or year as per the standardized call names listed in Appendix 4 of Conway (2011): tic-tic tic-tictic of Yellow Rail (Coturnicops noveboracensis); coo of Least Bittern (Ixobrychus exilis); whinny, per-weep, and keep of Sora (Porzana carolina); grunt and tick-it of Virginia Rail (Rallus limicola); pump-er-lunk of American Bittern (Botaurus lentiginosus); and owhoop of Pied-billed Grebe (Podilymbus podiceps); in that order. Similarly, call broadcasts in the Great Lakes-St. Lawrence region included the following: coo of Least Bittern; whinny, per-weep, and keep of Sora; grunt and tick-it of Virginia Rail; a mixture of burr-up of American Coot (Fulica americana) and wipe-out and keep of Common Gallinule (Gallinula galeata); and owhoop of Pied-billed Grebe; in that order. All participants received training to ensure as much as possible standard data collection and consistent species identification across observers. Details of the bird survey protocols are described in more detail in Bird Studies Canada (2009a,2009b, 2009c), which generally follow the North American protocol recommendations (Conway 2011).

\section{Analyses}

The response variable was the count of individuals of each species made within each of the three consecutive survey intervals at each station. We used generalized binomial $\mathrm{N}$-mixture models for repeated count data with negative binomial distributions to 
simultaneously evaluate covariates potentially related to abundance, availability, and detectability (Royle 2004, Chandler et al. 2011). The models consisted of three hierarchical levels: one described the total number of individuals that potentially use habitats around each station, referred to here as the abundance process; another described the proportion of total individuals present within plots during surveys, referred to here as the availability process; and another described the proportion of available individuals observed during surveys, referred to here as the detectability process (Chandler et al. 2011). We chose a negative binomial distribution because models with this distribution had lower Akaike's Information Criterion (AIC) values for each species compared with models using a Poisson distribution. During modeling, the count data from replicate surveys at each station in each year informed the availability process, whereas the repeated count data from the multiple 5-min intervals during each survey at each station in each year informed the detectability process (Fiske et al. 2015).

To generate a final best model for each species, we started with a global model that included region in each of the abundance, availability, and detectability processes; wind, temperature, cloud, date, quadratic effect of date (i.e., date $*$ date), date * region interaction, daylight, and time of day in the availability and detectability processes; year (as a continuous covariate) and year * region interaction in the abundance process; and survey interval in the detectability process. However, region and its interactions were included for only some of the species; see further details below. Then we created a set of candidate models by removing each explanatory variable one at a time from the detectability process, which produced a model set with the same number of models as there were variables in the detectability process. Next we chose the best approximating model from among these candidate models based on lowest AIC. We then performed the same process described above on the detectability variables in this best model, and so on, until no further reduction in AIC occurred. This yielded the final variables for the detectability process. We then carried out the same approach for all variables in the availability and abundance processes, while including all of the final variables in the detectability process of each model. In the end, we retained the best-fitting model structure for the detectability, availability, and abundance processes in a final best model for each species. We opted to develop final best models using this approach to minimize the total number of models that had to be run because computer run time was extremely prohibitive because of the complexity of the models and large sample size. We tested the overall fit of the global model for each species using parametric bootstrapping and the Freeman-Tukey fit statistic; $P$ values $>0.05$ indicated adequate fit (Fiske and Chandler 2015). We also evaluated the adequacy of models by generating abundance estimates and associated errors, and comparing them with previous estimates generated via other methods (e.g., Tozer 2013).

We included region in the abundance, availability, and detectability processes to account for differences in plot sizes and known or suspected differences in numbers of individuals, calling frequency, and chances of detecting individuals between the two regions. Similarly, we included year in the abundance process to account for known or suspected changes in abundance across years (e.g., Tozer 2013) and survey interval in the detectability process to account for known differences in detectability between intervals before, during, and after conspecific call broadcasts (Conway and Nadeau 2010). As the main focus of the study, we included wind, temperature, cloud, date, daylight, and time of day in the availability and detectability processes to describe daily, seasonal, and weather-related variation in availability and detectability.

Data were sufficient for analysis of Least Bittern, American Coot, and Common Gallinule only in the Great Lakes-St. Lawrence region; for Yellow Rail only in the Prairie region; and for Piedbilled Grebe, American Bittern, Virginia Rail, and Sora in both regions. Thus, region and its interactions were included in models only for the latter four species. Least Bittern, Common Gallinule, and Yellow Rail occurred, for the most part, in only one region or the other, resulting in insufficient sample size for analysis in at least one of the regions. By contrast, American Coot occurred in sufficient numbers in both regions, but in the Prairie region the number of individuals detected in each 5-min interval of each survey was not recorded, which precluded the information required for modeling detectability of the species in that region. We note that observers recorded unidentified Common Gallinules or American Coots as "MOOTs," but we did not consider these data in our analyses.

To explore relationships, we plotted species-level predicted values as a function of each covariate in the availability and detectability processes of final best models. To economize on space, we report these important results in Appendix 1 and limit our discussion of them to key points. To make generalized recommendations across all species of this elusive group, we summarized species-level predictions by plotting mean availability, mean detectability, and mean detection probability, i.e., availability * detectability $(\phi *$ $p$ ), as a function of selected values of each covariate, which we treat as the main focus of the study. We used intercept values for species where covariates did not appear in final best models when calculating mean detectability, mean availability, and mean detection probability. We included $95 \%$ confidence intervals on plots to illustrate uncertainty, except in some instances with interaction terms when we dropped the confidence intervals to make plots easier to interpret.

All analyses were performed using the $\mathrm{R}$ programming language ( $\mathrm{R}$ Development Core Team 2015). To facilitate model convergence and comparison of estimates across variables and species, we $\mathrm{z}$-transformed all of the covariates prior to analysis (Kéry and Chandler 2012). Models were fitted using the gpcount function in the package unmarked (Chandler et al. 2011, Fiske et al. 2015).

\section{RESULTS}

The data set consisted of 22,389 surveys conducted at 3571 stations along 813 routes over 8 years between 2008 and 2014 (Fig. 1). The majority of the surveys were in the Great Lakes-St. Lawrence region (15,553 of 22,389 surveys; $69 \%$ ) compared with the Prairie region (6856 surveys; 31\%). Correspondingly, there were more stations surveyed in total in the Great Lakes-St. Lawrence region (2172 stations) compared with the Prairie region (1399 stations). The number of surveys varied annually, with 2219 \pm 193 surveys per year (mean \pm SD) in the Great Lakes-St. Lawrence region and $979 \pm 550$ surveys per year in the Prairie 
Fig. 2. Number of stations occupied per year by different species and number of stations surveyed per year regardless of occupancy, used to form empirically based sampling protocols to maximize detection probability of secretive marsh birds within two regions of southern Canada and the Great Lakes states, 2008 to 2014.

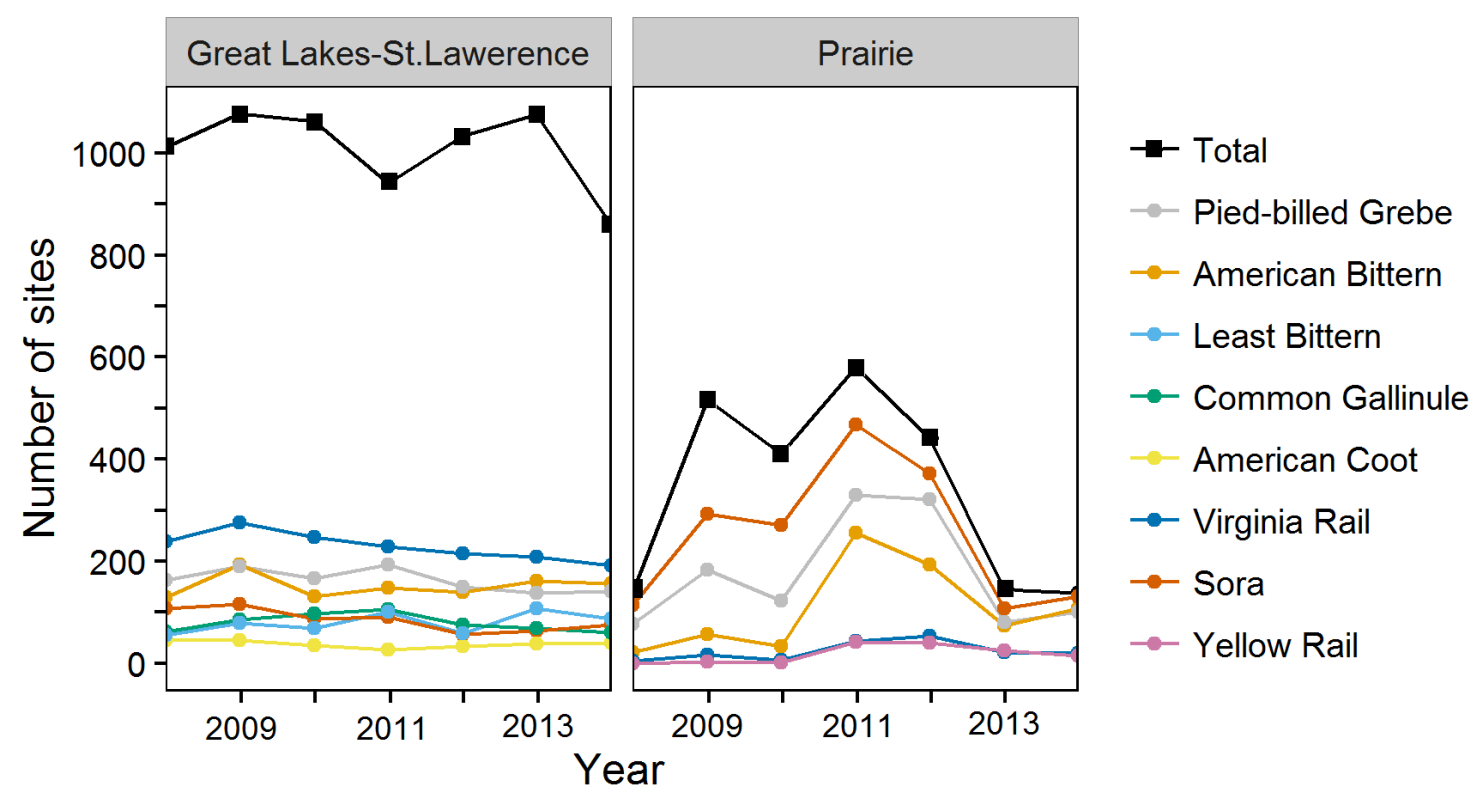

region (Fig. 2). Likewise, there were more stations surveyed per year on average in the Great Lakes-St. Lawrence region (1008 \pm 82 stations per year) compared with the Prairie region (338 \pm 193 stations per year; Fig. 2).

Elusive marsh birds were more frequently encountered during surveys in the Prairie region compared with the Great Lakes-St. Lawrence region, with multiple species each being detected at $\sim 50 \%-95 \%$ of stations in several of the years in the Prairie region compared with a maximum of only $\sim 25 \%$ for any of the species in any of the years in the Great Lakes-St. Lawrence region (Fig. 2). The frequency of occurrence of particular species also differed among the regions, with Sora being the most frequent in the Prairie region, followed by Pied-billed Grebe, American Bittern, Virginia Rail, and Yellow Rail (Fig 2). By contrast, Virginia Rail was the most frequent in the Great Lakes-St. Lawrence region, followed by Pied-billed Grebe, American Bittern, Sora, Common Gallinule, Least Bittern, and American Coot (Fig. 2).

The distribution of each covariate across surveys within each region was similar, with two exceptions (Fig. 3). There were relatively more evening surveys in the Great Lakes-St. Lawrence region, and temperatures tended to be cooler during surveys in the Prairie region (Fig. 3).

The global model fit adequately for all species $(P=0.3$ to 0.6$)$ except Sora $(P<0.01)$, and model-predicted abundances and associated errors appeared to be reasonable (Fig. 4). Thus, we report results for Sora below, but recommend caution be used during interpretation. Plus, we note that we included results for Sora in our calculations of mean detection probability across all species below, given that Sora was only 1 of 8 species included in the calculations and mean detection probability across all species was similar whether Sora was included or excluded.
Survey interval was retained in the detectability process of the best supported model for each species, as was region in the availability and detectability processes for species when data allowed for analysis across both regions (Appendix 1). Not surprisingly, detectability was highest during the 5-min interval with conspecific call broadcasts, with two exceptions (Appendix 1). Detectability of American Bittern and Yellow Rail in the Prairie region was very similar among all 3 of the 5-min intervals, despite conspecific call broadcasts in the middle 5-min interval (Appendix 1). Composition of the remaining 6 covariates retained in final best models varied among species (Appendix 1). Plus, relationships between covariates with detection and availability varied among species, with patterns being most variable as a function of date, temperature, and daylight, and less variable as a function of time of day, wind, and cloud (Appendix 1).

Across all species, on average, detection probability (i.e., availability $*$ detectability, or $\phi^{*} p$ ) remained relatively high in the Great Lakes-St. Lawrence region from the beginning of May through until mid-June and then fell throughout the remainder of the season until the end of June (Fig. 5). This was a function of higher detectability and/or availability early in the season for Pied-billed Grebe, American Bittern, American Coot, and Sora, followed by higher detectability and/or availability in midseason for Least Bittern, Common Gallinule, and Virginia Rail, and then lower detectability and/or availability later in the season among nearly all of the species (Appendix 1). By contrast, mean detection probability across all species was lowest in the Prairie region in mid-May and then increased throughout the remainder of the season until the end of June (Fig. 5). This was due to higher detectability and/or availability later in the season for Virginia Rail and Yellow Rail, combined with very little or almost no change in detectability and/or availability over the season among all of the rest of the species (Appendix 1). 
Fig. 3. Number of stations surveyed as a function of covariates used to form empirically based sampling protocols to maximize detection probability of secretive marsh birds within two regions of southern Canada and the Great Lakes states, 2008 to 2014. Variables are defined in the Methods section.
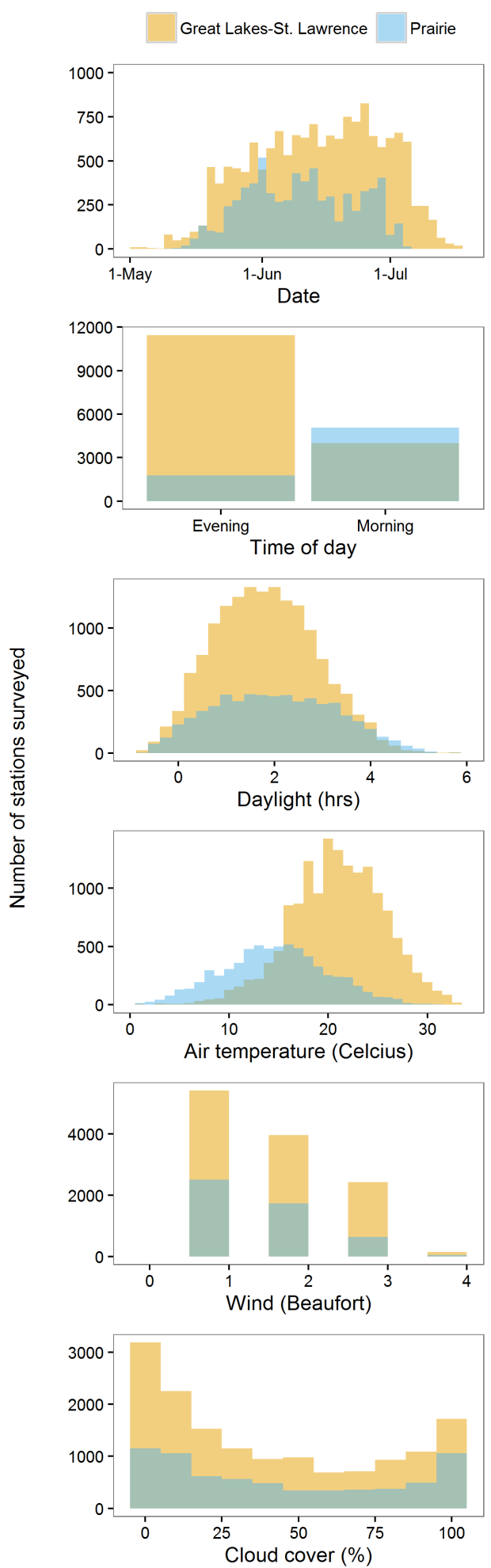

Fig. 4. Model-predicted abundances and associated 95\% confidence intervals from models used to form empirically based sampling protocols to maximize detection probability of secretive marsh birds within two regions of southern Canada and the Great Lakes states, 2008 to 2014.

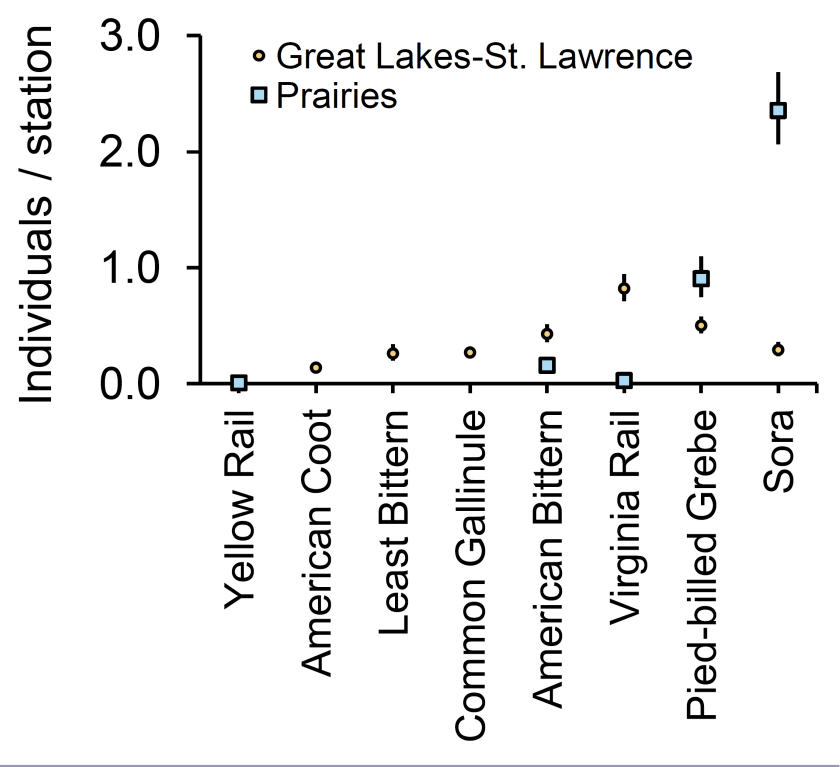

Mean detection probability across all species was also higher during darkness compared with light (Fig. 5), on account of higher detectability and/or availability during darkness among all of the species (Appendix 1). By contrast, mean detection probability across all species did not vary significantly according to temperature, cloud cover, or wind, or during morning versus evening (Fig. 5).

\section{DISCUSSION}

Mean detection probability across all species varied as a function of time of season within each region and as a function of daylight. By contrast, we found much less or almost no variation in mean detection probability across all species as a function of time of day (i.e., morning versus evening), temperature, wind, and cloud. Many of these model-based predictions are not surprising because the relationships have been reported elsewhere (see Conway and Gibbs 2011 for an excellent review). Plus, the results in relation to time of day, temperature, and wind are not surprising because of the design-based limits imposed on these influences by the standardized North American protocol (Conway 2011). However, some of the findings are novel within the regions that we studied, and as we outline below, are quite useful for refining and improving marsh bird field survey protocols, including the standardized North American protocol (Conway 2011) in these areas.

In this paper, and in particular in the discussion and recommendations below, we focus on maximizing detections across all species. This is desirable for the various broad-scale marsh bird monitoring programs active throughout southern Canada and the Great Lakes states because the programs strive 
Fig. 5. Mean detectability (p), availability $(\phi)$, and detection probability $(\phi * p)$ across 8 secretive marsh bird species as a function of seasonal, daily, and weather-related covariates within two regions of southern Canada and the Great Lakes states, 2008 to 2014. Note that an interaction with region was included in models only for date, so only results for date are shown separately for each region. See the text for covariate definitions. Shadows are $95 \%$ confidence limits. Also be aware that these summaries may only be useful for simultaneously optimizing detection probability across all of the species. Conditions for optimizing detection probability of individual species or smaller groups of species may differ. See the text for further discussion.
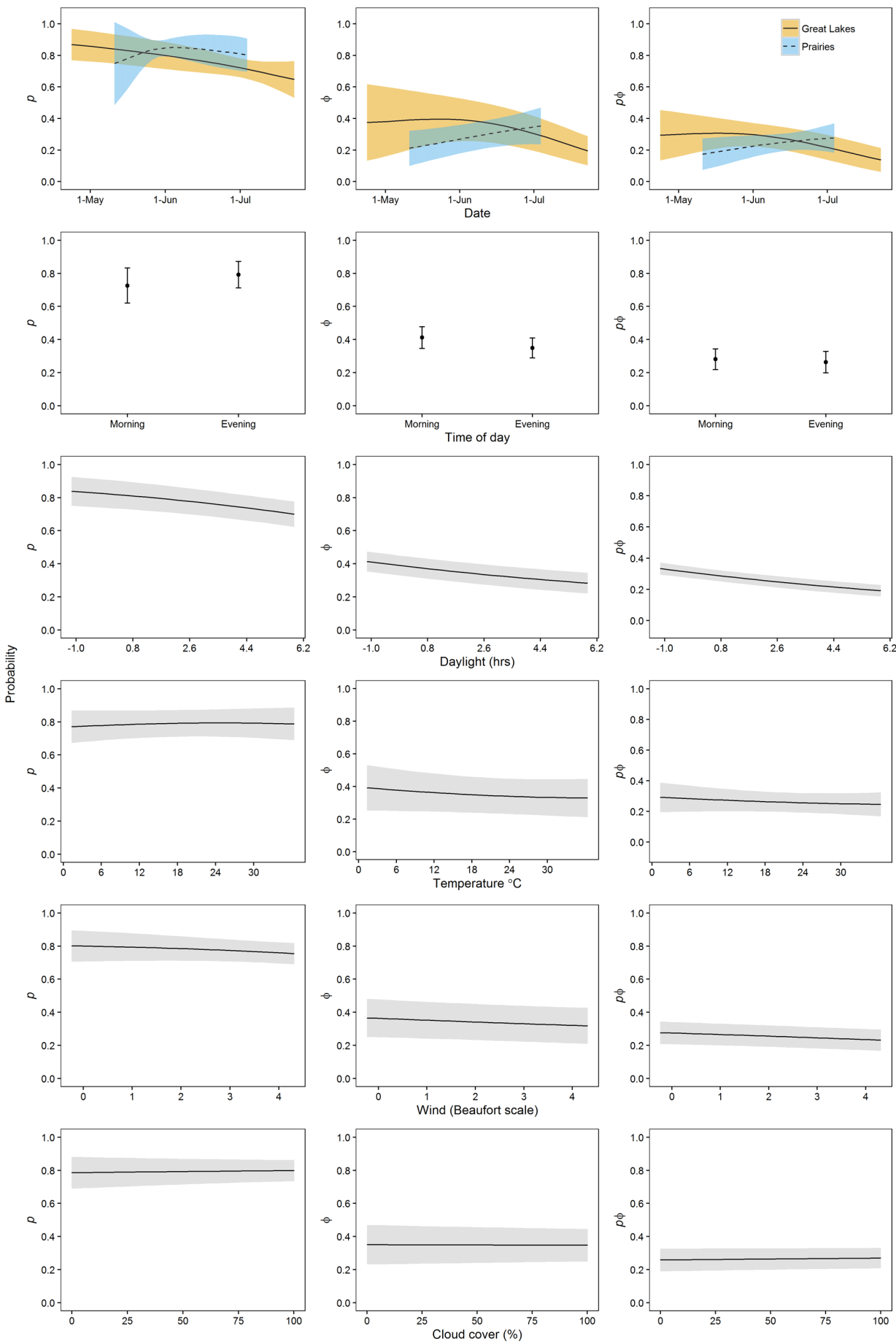
to track all marsh bird species present in their regions. By contrast, the approach may not be the most effective for maximizing detections of individual species or smaller groups of species for other purposes. In these instances, information in Appendix 1 for the species of interest should be consulted for guidance.

We found that average detection probability across all species was highest in the Great Lakes-St. Lawrence region from the beginning of May until mid-June, and then fell throughout the remainder of the season until the end of June. Based on these patterns, the most effective approach to maximize detection probability across all of the species in the Great Lakes-St. Lawrence region is to conduct surveys between the local average onset of nesting for most species, which is mid- to late May depending on the year, and mid-June. Surveys during the earlier part of this period will maximize detection probability for species with early calling phenology including Pied-billed Grebe, American Bittern, American Coot, and Sora, whereas surveys during the latter part of the period will maximize detection probability for species with late calling phenology including Least Bittern, Common Gallinule, and Virginia Rail. Surveys could be conducted as late as the second half of June if the focus is on late species, particularly Common Gallinule and Virginia Rail, because detection probability for these species was high throughout June. However, detection probability for most species will be lower, on average, in the second half of June, and surveys should not be conducted for any species after the end of June in the Great Lakes-St. Lawrence region.

By contrast, we found that average detection probability across all species was lowest in the Prairie region in mid-May and then increased throughout the remainder of the season until the end of June. Based on these patterns, the most effective approach to maximize detection probability across all of the species in the Prairie region is to conduct surveys in June. Surveys during any part of June will maximize detection probability for Pied-billed Grebe, American Bittern, and Sora, whereas surveys during the latter part of June will maximize detection probability for species with late calling phenology, including Virginia Rail and Yellow Rail. Surveys could be conducted as early as the second half of May if the focus is on Pied-billed Grebe, American Bittern, and Sora, and the surveys begin after the local average onset of nesting, because detection probability for these species was high during that period. It may be possible to conduct surveys after the end of June in the Prairie region, given that detection probability of all species was still high, or was still increasing at the end of June, but not beyond the end of the first week of July, because detection probability appears to drop dramatically for some species after that time (K. Drake, personal observation).

We also found that mean detection probability across all species was higher during darkness compared to light. Most marsh bird sampling protocols, including the standardized North American protocol (Conway 2011), recommend conducting surveys no earlier than 0.5 hours before sunrise and no later than 0.5 hours after sunset. However, we found that detectability and/or availability of all of the species was highest during darkness 1 hour prior to sunrise and 1 hour following sunset. In fact, detectability and/or availability continued to increase further into the night at each end of the day for all of the species. Indeed, more detailed study of Yellow Rail confirmed that detection probability is highest throughout the night compared with daytime (K. Drake, unpublished data), a result that also applies to Sora and Virginia Rail, but not to American Bittern and Pied-billed Grebe, which are more active during crepuscular hours (K. Drake, unpublished data). Based on the above patterns, the most effective approach to maximize detection probability for all of the species is to conduct surveys during the 1 hour of dark before sunrise or after sunset, or as close to these two periods during the day as possible. Potential drawbacks to this approach include nighttime safety issues, and the risk that detection of diurnally active species of interest will be low or will not occur at night.

Lastly, we found that mean detection probability across all species did not vary significantly according to temperature (range: $0-30^{\circ}$ C), cloud cover $(0-100 \%)$, or wind $(0-20 \mathrm{kph})$, or during morning versus evening periods. These findings indicated that, on average, temperature, cloud, wind, and time of day have little influence within the design-based limits imposed by the standardized North American protocol (Conway 2011) on detection probability across all of the marsh bird species that we studied in the Great Lakes-St. Lawrence and Prairie regions. More specifically, the findings suggest that these factors have little influence on detection probability across all species provided that surveys are conducted between $\sim 0^{\circ} \mathrm{C}$ and $30^{\circ} \mathrm{C}$ and at wind speeds less than Beaufort 3 or $<20 \mathrm{kph}$, which were the conditions during nearly all of the surveys in our study. These findings have immediate practical advantages. By surveying in the morning and in the evening, one can obtain much larger sample sizes, not only in terms of the number of stations sampled, but also in terms of the number of visits, than if surveys were restricted to one time period or the other. In addition, some marsh bird sampling protocols recommend that surveys occur only when temperatures are above certain minimum values, for example, above $16^{\circ} \mathrm{C}$ (Bird Studies Canada 2009a,2009b), but our results suggest that these restrictions can be relaxed down to $0^{\circ} \mathrm{C}$ at the minimum. This larger temperature range will also allow for larger sample sizes by increasing opportunities for surveying. Potential drawbacks to this approach are the risk that detection probability for other species of interest, particularly songbirds, may be undesirably low in the evening.

We used a large amount of data collected over many years by a large network of citizen scientists and staff to estimate seasonal, daily, and weather-related variation in detection probability of several marsh bird species throughout the Prairie and Great Lakes-St. Lawrence regions. The results suggest various improvements to marsh bird field survey protocols in these regions, which contribute to conservation of wetland birds at various scales from local single-species studies to the continental North American Marsh Bird Monitoring Program. Amassing such a large and useful data set without Bird Studies Canada's regional marsh monitoring programs would not have been possible, which highlights the utility of these ongoing, long-term programs for monitoring wildlife.

Responses to this article can be read online at: http://www.ace-eco.org/issues/responses.php/875 


\section{Acknowledgments:}

We are grateful for the dedication of hundreds of Prairie, Great Lakes, and Québec Marsh Monitoring Program participants and staff, whose collective effort made the study possible. We extend a debt of gratitude to hundreds of landowners that granted access to private property. We are also grateful for the coordination and promotion of the programs by Kathy Jones, Andrew Coughlan, and a large team of regional coordinators throughout the Great Lakes basin; and for past coordination of the programs by Russ Weeber, Steve Timmermans, and Ryan Archer in the Great Lakes, and Catherine Poussart in Québec. Bird Studies Canada is grateful for the support of its marsh monitoring programs by the Government of Canada through the federal Department of the Environment, Alberta Conservation Association, Alberta North American Waterfowl Management Plan Science Fund, Brant Waterways Foundation, Ducks Unlimited Canada (particularly the Institute for Wetlands and Waterfowl Research), Great Lakes Commission, Great Lakes Protection Fund, Great Lakes Restoration Initiative, Great Lakes Sustainability Fund, Great Lakes United, Government of Ontario, Manitoba Sustainable Development Innovations Fund, National Audubon Society, Ontario Eastern Habitat Joint Venture, Ontario Trillium Foundation, Saskatchewan Fish and Wildlife Development Fund, Saskatchewan Water Security Agency, Service Canada Summer Jobs Program, Science Horizons Program, TD Friends of the Environment Foundation, U.S. Environmental Protection Agency, Wetland Habitat Fund, and Wildlife Habitat Canada. Finally, we are especially grateful for support during the preparation of this paper from the U.S. Fish and Wildlife Service Webless Migratory Gamebird Program.

\section{LITERATURE CITED}

Bird Studies Canada. 2009a. Marsh Monitoring Program participant's handbook for surveying marsh birds. Revised 2008. Bird Studies Canada in cooperation with Environment Canada and the U.S. Environmental Protection Agency, Port Rowan, Ontario, Canada.

Bird Studies Canada. 2009b. Québec Marsh Monitoring Program training kit and instructions for surveying marsh birds and their habitats. 2008 edition Québec. Bird Studies Canada in cooperation with Environment Canada, Port Rowan, Ontario, Canada.

Bird Studies Canada. 2009c. Prairie and Parkland Marsh Monitoring Program training kit and instructions for surveying marsh birds and their habitats. Revised 2010. Bird Studies Canada, Saskatoon, Saskatchewan, Canada.

Bird Studies Canada. 2016. Marsh Monitoring Program. Bird Studies Canada, Port Rowan, Ontario, Canada. [online] URL: http://www.birdscanada.org/volunteer/natmmp/index.jsp?lang=EN

Chandler, R. B., J. A. Royle, and D. I. King. 2011. Inference about density and temporary emigration in unmarked populations. Ecology 92:1429-1435. http://dx.doi.org/10.1890/10-2433.1

Conway, C. J. 2011. Standardized North American marsh bird monitoring protocol. Waterbirds 34:319-346. http://dx.doi. org/10.1675/063.034.0307
Conway, C. J., and J. P. Gibbs. 2011. Summary of intrinsic and extrinsic factors affecting detection probability of marsh birds. Wetlands 31:403-411. http://dx.doi.org/10.1007/s13157-011-0155$\mathrm{x}$

Conway, C. J., and C. P. Nadeau. 2010. Effects of broadcasting conspecific and heterospecific calls on detection of marsh birds in North America. Wetlands 30:358-368. http://dx.doi. org/10.1007/s13157-010-0030-1

Cooper, M. J., D. G. Uzarski, and V. J. Brady. 2014. Implementing Great Lakes coastal wetland monitoring. Pages 3-11 in 2014 Great Lakes Wetlands Day proceedings, February 2014. Prepared by members of the Great Lakes Wetlands Conservation Action Plan, Toronto, Ontario, Canada. [online]: URL: http://glwcap.ca/ files/2013/10/WetlandsDayProceedings.pdf.

Fiske, I., and R. Chandler. 2015. Overview of unmarked: an $R$ package for the analysis of data from unmarked animals. $\mathrm{R}$ Project for Statistical Computing, Vienna, Austria. [online]: URL: http:// cran.r-project.org/web/packages/unmarked/vignettes/unmarked. pdf

Fiske, I., R. Chandler, D. Miller, A. Royle, and M. Kéry. 2015. 'Package unmarked.' R Project for Statistical Computing, Vienna, Austria. [online]: URL: http://cran.r-project.org/web/packages/ unmarked/unmarked.pdf

Kéry, M., and R. Chandler. 2012. Dynamic occupancy models in unmarked. R Project for Statistical Computing, Vienna, Austria.[online]: URL: http://cran.r-project.org/web/packages/ unmarked/vignettes/colext.pdf

McCallum, D. A. 2005. A conceptual guide to detection probability for point counts and other count-based surveys. USDA Forest Service Gen. Tech. Rep. PSW-GTR-191. U.S. Department of Agriculture Forest Service, Washington, D.C., USA. [online]: URL: http://www.fs.fed.us/psw/publications/documents/psw_gtr191/ Asilomar/pdfs/754-761.pdf

Nadeau, C. P., C. J. Conway, B. S. Smith, and T. E. Lewis. 2008. Maximizing detection probability of wetland-dependent birds during point-count surveys in northwestern Florida. Wilson Journal of Ornithology 120:513-518. http://dx.doi.org/10.1676/07-041.1

Nichols, J. D., L. Thomas, and P. B. Conn. 2009. Inferences about landbird abundance from count data: recent advances and future directions. Pages 201-235 in D. L. Thomson, E. G. Cooch, and M. J. Conroy, editors. Modeling demographic processes in marked populations. Springer, New York, New York, USA. http://dx.doi. org/10.1007/978-0-387-78151-8_9

R Development Core Team. 2015. R: a language and environment for statistical computing. R Foundation for Statistical Computing, Vienna, Austria. [online]: URL: http://www.R-project.org

Rehm, E. M., and G. A. Baldassarre. 2007. Temporal variation in detection of marsh birds during broadcast of conspecific calls. Journal of Field Ornithology 78:56-63. http://dx.doi.org/10.1111/ j.1557-9263.2006.00085.x

Royle, J. A. 2004. Generalized estimators of avian abundance from count survey data. Animal Biodiversity and Conservation 27:1. 
Steidl, R. J., C. J. Conway, and A. R. Litt. 2013. Power to detect trends in abundance of secretive marsh birds: effects of species traits and sampling effort. Journal of Wildlife Management 77:445-453. http://dx.doi.org/10.1002/jwmg.505

Tacha, T. C., and C. E. Braun, editors. 1994. Migratory shore and upland game bird management in North America. International Association of Fish and Wildlife Agencies, Washington, D.C., USA.

Tozer, D. C. 2013. The Great Lakes Marsh Monitoring Program 1995-2012, 18 years of surveying birds and frogs as indicators of ecosystem health. Bird Studies Canada, Port Rowan, Ontario, Canada. [online]: URL: http://www.birdscanada.org/download/ GLMMPreport.pdf

Tozer, D. C. 2016. Marsh bird occupancy dynamics, trends, and conservation in the southern Great Lakes basin: 1996 to 2013. Journal of Great Lakes Research 42:136-145. http://dx.doi. org/10.1016/j.jglr.2015.10.015

Wisconsin Bird Conservation Initiative. 2015. Wisconsin Marshbird Survey. Wisconsin Bird Conservation Initiative, Ashland, Wisconsin, USA. [online]: URL: http://wiatri.net/ projects/birdroutes/marshbirds.htm 


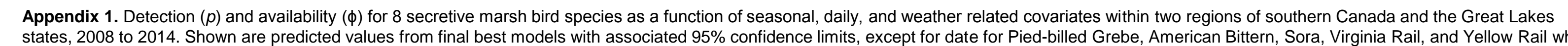

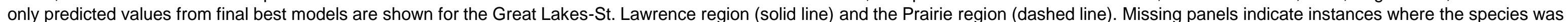

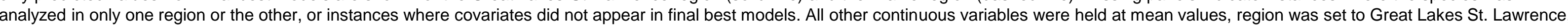
survey interval was set to the first 5-min passive listening period, and time of day was set to evening. See text for covariate definitions.
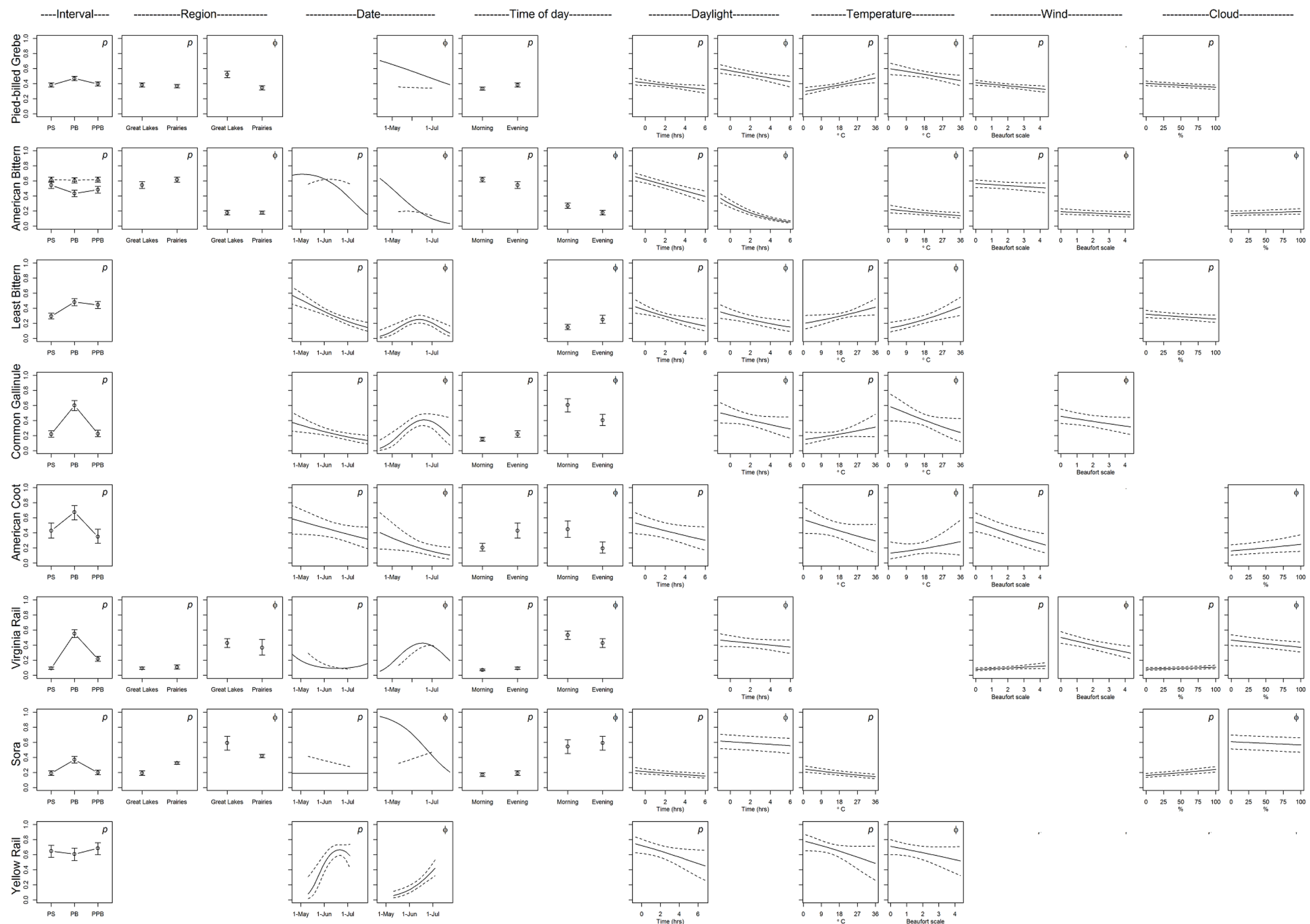